\title{
Uncommon Etiology of Chronic Wheeze
}

\author{
Varuna Jethani, Rakhee Sodhi Khanduri', Ankit Aggarwal', Suchita Pant ${ }^{1}$

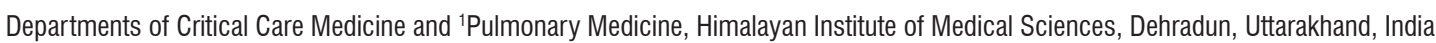

\section{Abstract}

Endobronchial tuberculosis (TB) refers to TB infection of the tracheobronchial tree. We report the case of a 62-year-old immunocompetent patient of chronic cough with normal X-ray. She did not have any systemic complaints suggestive of TB. Her diagnosis was made when she underwent bronchoscopy to look for any endobronchial cause of cough. It revealed complete caseation in the airways. Microscopically and pathologically, it was confirmed to be tubercular. The patient improved clinically on antitubercular therapy.

Keywords: Cough, endobronchial tuberculosis, normal X ray

\section{INTRODUCTION}

Endobronchial tuberculosis (TB) alludes to tuberculous contamination of the tracheobronchial tree. The diagnosis of such disease is difficult because usually chest radiograph is normal. Computed tomography (CT) and bronchoscopy are the sole tools of diagnosing this disease. The treatment of this disease remains the same as pulmonary TB. However, utmost care should be taken to prevent tracheobronchial stenosis or obstruction. ${ }^{[1,12]}$

\section{Case Report}

A 62-year-old, nonsmoker, nondiabetic, hypertensive female presented to our outpatient department (OPD) with complaints of dry cough and progressively increasing dyspnea for 3-4 months. There were no complaints of fever, chest pain, decreased appetite, or weight loss associated with it. General physical examination was normal. Respiratory system examination was normal except for the harsh vesicular breath sounds and wheezing present bilaterally. It was more in the mammary and infrascapular regions. Routine blood examinations were also normal. Chest X-ray was within normal limits as shown in Figure 1. Spirometry with reversibility showed moderate obstruction with reversibility. Her ENT examination was also unremarkable.

The patient was started on inhaled glucocorticosteroid plus long-acting beta- 2 agonist considering the possibility of late-onset bronchial asthma. After 1 month, she came for follow-up in OPD.

\begin{tabular}{|l|l|}
\hline \multicolumn{2}{|c|}{ Access this article online } \\
\hline Quick Response Code: & Website: \\
\hline & www.ijrconline.org \\
\hline & \\
\hline
\end{tabular}

She reported improvement in dyspnea, but cough worsened. There was no improvement in examination finding of wheezing and the presence of harsh vesicular breath sounds. She was admitted to the hospital for further evaluation. Considering the possibility of tracheomalacia, she was started on continuous positive airway pressure (CPAP) of $7 \mathrm{cmH}_{2} \mathrm{O}$. After application of CPAP, her chest was clear on auscultation, and she reported improvement in cough. A bronchoscopy was done to confirm tracheomalacia. Thick white patches were seen in the lower part of the trachea and carina, with slight distortion of the carina, a small globular growth near the carina, and narrowing of the right upper-lobe bronchus in addition to tracheomalacia [Figure 2]. Bronchoalveolar lavage (BAL) was taken from the right upper lobe. Brush smear and biopsy were done and sent for investigation.

BAL report showed acid-fast bacilli and brush smear cytology, and biopsy also revealed tubercular pathology. She was started on antitubercular treatment (ATT) along with the continuation of CPAP support. She improved symptomatically and tolerated ATT well. She was discharged on ATT and CPAP support at home.

On follow-up after 1 month, she improved symptomatically with marked improvement in cough. There were no harsh vesicular breath sounds and rhonchi heard on auscultation. CPAP was also stopped. She was given four drugs, namely rifampicin,

Address for correspondence: Dr. Rakhee Sodhi Khanduri, Department of Pulmonary Medicine, Himalayan Institute of Medical Sciences, Dehradun, Uttarakhand, India. E-mail: rakhee.sodhi@gmail.com

This is an open access journal, and articles are distributed under the terms of the Creative Commons Attribution-NonCommercial-ShareAlike 4.0 License, which allows others to remix, tweak, and build upon the work non-commercially, as long as appropriate credit is given and the new creations are licensed under the identical terms.

For reprints contact: reprints@medknow.com

How to cite this article: Jethani V, Khanduri RS, Aggarwal A, Pant S. Uncommon etiology of chronic wheeze. Indian J Respir Care 2019;8:63-5. 
isoniazid, ethambutol, and pyrazinamide in intensive phase for 2 months and three drugs, namely rifampicin, isoniazid, and ethambutol in continuation phase for 4 months.

At the end of 6 months, repeat bronchoscopy showed marked improvement with complete resolution of all lesions [Figure 3].

\section{Discussion}

Endobronchial TB is caused in the bronchus either directly from a nearby infection of lung parenchyma or by the sputum which is infectious. Usually, the main and upper bronchi are involved, while the lower trachea is involved very rarely. ${ }^{[1]}$ It usually affects females in middle and elderly ages. ${ }^{[2-4]}$ Our patient was also an elderly lady. Patients suffering from endobronchial TB complain of cough with sputum production, chest torment, blood in sputum, laziness, fever, and difficulty in breathing. These may be acute in onset. The differential diagnosis can vary from pneumonia caused by bacteria to asthma, ${ }^{[5,6]}$ or foreign body aspiration. ${ }^{[5,7]}$ The clinical presentation can be subtle too, resembling lung cancer ${ }^{[8]}$ Our patient never had fever and hence the infectious cause of her cough was not considered.

A barking cough has been described in roughly two-thirds of patients with endobronchial illness, regularly went with by sputum generation. ${ }^{[6-9]}$ Seldom, patients develop bronchorrhea, which is generation of $>500 \mathrm{~mL} /$ day of sputum. ${ }^{[9]} \mathrm{In}$ a few cases, caseous substance from endobronchial injuries or calcific substance from the expansion of calcific nodes into the bronchi is expectorated, which is known as lithoptysis. Patients may also complain of blood in sputum and wheezing. Patients can develop acute pain in the chest which can be due to rupture of lymph node. If a patient complains of difficulty in breathing, one must suspect lung collapse or any obstruction. Our patient only had complaints of cough and wheezing.

Systemic examination of a patient with endobronchial TB can reveal decreased breath sounds, rhonchi, or wheezing. The wheeze is usually low pitched, monophonic, and constant. Our patient had monophonic wheeze.

As endobronchial lesions need not warrant extensive involvement of lung parenchyma, a normal chest radiograph is observed in $10 \%-20 \%$ of cases. In such cases, CT scanning may demonstrate endobronchial lesions or stenosis and rarely fistulas. The foremost common radiographic finding of endobronchial TB is an upper-lobe consolidation with cavitation. This may spread to ipsilateral lower lobe.

In patients having primary $\mathrm{TB}$ presenting as endobronchial $\mathrm{TB}$, segmental atelectasis is usually seen. Lung collapse is more frequent in the right middle lobe and the anterior segment of the right upper lobe. The chest X-ray of our patient was normal.

The diagnosis of endobronchial TB may be established by bronchoscopy; findings may include edematous-hyperemic lesions (with or without ulceration or fibrosis) or nonspecific bronchitis. ${ }^{[10]}$ Caseous material or narrowing of bronchial lumen may be visualized. ${ }^{[11]}$ The presence of edema, increased

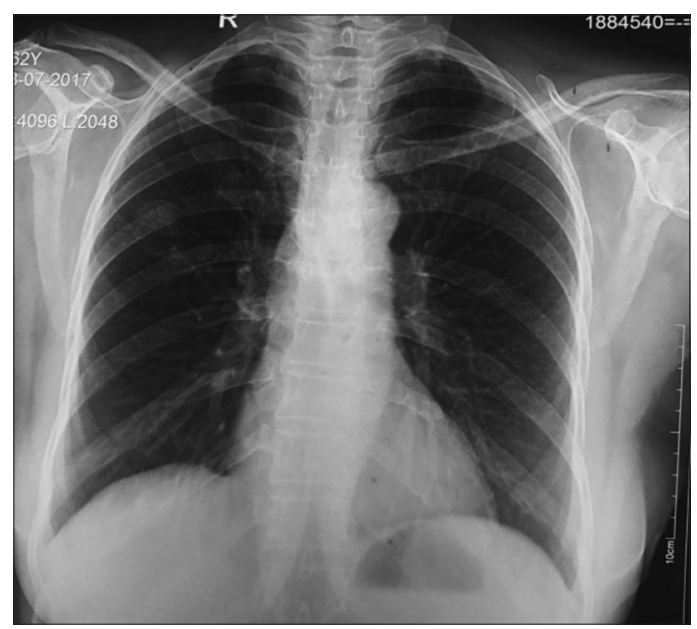

Figure 1: Chest X-ray of the patient at presentation

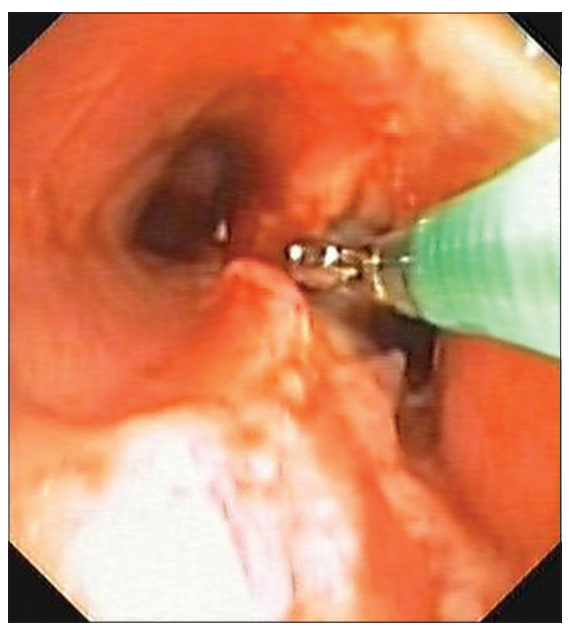

Figure 2: Bronchoscopic view showing biopsy being taken from growth in trachea

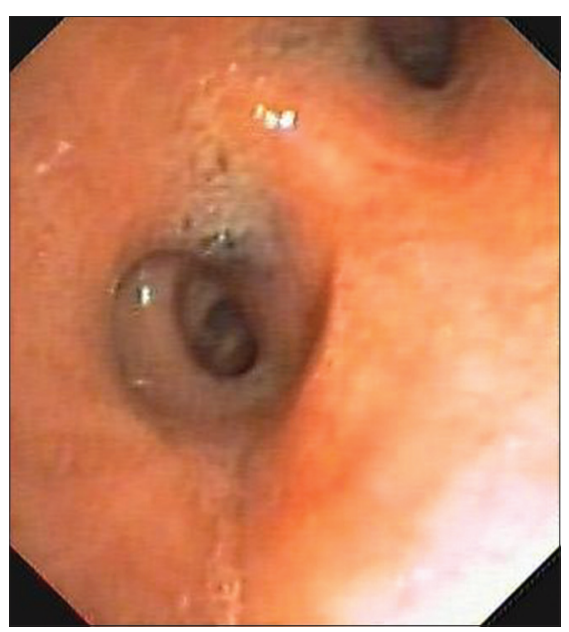

Figure 3: Bronchoscopic view of airways after 6 months of antitubercular therapy

redness, and caseation can eventually lead to bronchial stenosis or obstruction. This can occur even when ATT has been 
Jethani, et al.: Uncommon etiology of chronic wheeze

started. ${ }^{[1]]}$ Taking brush smears or bronchoalveolar lavage can clinch the diagnosis. ${ }^{[12]}$

There is no difference in the treatment of endobronchial TB from normal pulmonary TB. Corticosteroids may slow down fibrosis and decrease the chances of development of stenosis. However, if a patient has developed stenosis leading to complications, the patency of airways must be made surgically or by bronchoscopically. ${ }^{[12]}$ Our patient did not require any surgery. She improved with anti-tubercular therapy.

\section{Conclusion}

"All that wheezes is not asthma" should always be kept in mind when patients present with a wheeze. The differential diagnosis must include airway pathology such as endobronchial TB, especially when they are unresponsive to usual therapy.

\section{Declaration of patient consent}

The authors certify that they have obtained all appropriate patient consent forms. In the form the patient(s) has/have given his/her/ their consent for his/her/their images and other clinical information to be reported in the journal. The patients understand that their names and initials will not be published and due efforts will be made to conceal their identity, but anonymity cannot be guaranteed.

\section{Financial support and sponsorship}

Nil.

\section{Conflicts of interest}

There are no conflicts of interest.

\section{RefERENCES}

1. Hoheisel G, Chan BK, Chan CH, Chan KS, Teschler H, Costabel U, et al. Endobronchial tuberculosis: Diagnostic features and therapeutic outcome. Respir Med 1994;88:593-7.

2. Auerbach O. Tuberculosis of the trachea and major bronchi. Am Rev Tuberc 1949;60:604-20.

3. Siow WT, Lee P. Tracheobronchial tuberculosis: A clinical review. J Thorac Dis 2017;9:E71-7.

4. Kashyap S, Mohapatra PR, Saini V. Endobronchial tuberculosis. Indian J Chest Dis Allied Sci 2003;45:247-56.

5. Caglayan S, Coteli I, Acar U, Erkin S. Endobronchial tuberculosis simulating foreign body aspiration. Chest 1989;95:1164.

6. Matthews JI, Matarese SL, Carpenter JL. Endobronchial tuberculosis simulating lung cancer. Chest 1984;86:642-4.

7. Van den Brande PM, Van de Mierop F, Verbeken EK, Demedts M. Clinical spectrum of endobronchial tuberculosis in elderly patients. Arch Intern Med 1990;150:2105-8.

8. So SY, Lam WK, Sham MK. Bronchorrhea. A presenting feature of active endobronchial tuberculosis. Chest 1983;84:635-6.

9. Williams DJ, York EL, Nobert EJ, Sproule BJ. Endobronchial tuberculosis presenting as asthma. Chest 1988;93:836-8.

10. Chung HS, Lee JH. Bronchoscopic assessment of the evolution of endobronchial tuberculosis. Chest 2000;117:385-92.

11. Albert RK, Petty TL. Endobronchial tuberculosis progressing to bronchial stenosis. Fiberoptic bronchoscopic manifestations. Chest 1976;70:537-9.

12. Lee P. Endobronchial tuberculosis. Indian J Tuberc 2015;62:7-12. 